\title{
Periconia hispidula A New Semiarid Biocatalyst for the Reduction of Prochiral Aromatic Ketone
}

\section{Serly $\mathbf{S}^{1}$, Luis Fernando $\mathbf{P G}^{2}$, Angelica $\mathrm{L}^{1}$, Heiddy $\mathrm{MA}^{1}$ and Iván Sergio $\mathrm{CG}^{{ }^{*}}$}

${ }^{1}$ Department of Exact (Dexas), Natural Products Laboratory (Lapron), Brazil

${ }^{2}$ Department of Biological Sciences, Laboratory of Microbiology, State University of Feira de Santana (UEFS), Bahia, Brazil

"Corresponding author: Ivan Sergio CG, Department of Exact (Dexas), Natural Products Laboratory (Lapron), Brazil, Tel: +55-75992763491; E-mail: sicolas@yahoo.com

Received: December 02, 2017; Accepted: December 20, 2017; Published: January 05, 2018

Copyright: (c) 2018 Serly S, et al. This is an open-access article distributed under the terms of the Creative Commons Attribution License, which permits unrestricted use, distribution, and reproduction in any medium, provided the original author and source are credited.

\begin{abstract}
The ability of fungus Periconia hispidula (42/07), isolated at the semi-arid of BAHIA in Brazil, to biotransform acetophenone and its derivatives has been studied. The influence of reaction parameters (mean, time, amount of substrate) on the conversion and enantioselectivity of acetophenone reduction was initially investigated. By comparison between culture media (optimized YM / BD / BD supplemented with $\mathrm{Fe}^{2+}$ ) BD medium supplemented with $\mathrm{Fe}^{2+}(0.02 \mathrm{~g} / \mathrm{L})$ was selected. From the growth curve, the incubation time prior to addition of substrate (4 and 7 days) was determined. The best conversion results for obtaining the (S)-1-phenylethanol, with enantiomeric excess of $98 \%$ were reached after four days of previous incubation of the microorganism. The influence of the amount of acetophenone $(20 \mu \mathrm{L}$ to $200 \mu \mathrm{L})$ was also analyzed with the objective of evaluating the toxicity of the substrate. Substrate amounts greater than $100(0.1 \%)$ were found to have resulted in conversion and enantioselectivity dropping. The biocatalyst was also tested against 20 prochiral ketones: 2-, 3- and 4-nitroacetophenone; 2-, 3- and 4methylacetophenone; 2-, 3- and 4-methoxyacetophenone; 2-, 3- and 4-bromoacetophenone; 2-, 3- and 4fluoracetophenone; 2,4-dimethylacetophenone; 2,5-dimethylacetophenone and 4-ethylacetophenone. Conversions of chiral alcohols ranged from $56 \%$ to $99 \%$ with enantiomeric excesses of 54 to over $99 \%$, demonstrating that the fungus Periconia hispidula is a promising stereoselective biocatalyst for application in reduction processes of carbonyl compounds.
\end{abstract}

Keywords: Microorganisms; Periconia hispidula; Biocatalyst; Bioreduction

\section{Introduction}

Biocatalysis is currently a prominent methodology for the synthesis of a number of chemical products, especially the enantiomerically pure substances [1]. Among these compounds are chiral alcohols, which can be used as precursors of a variety of drugs and agrochemicals of more complex structure such as ezetimibe (cholesterol reduction), taxol (anticancer) citalopram (antidepressant), (S)-propanolol (antihypertensive), among others $[2,3]$.

One of the possible biocatalytic methods to obtain chiral alcohols is the enantioselective reduction of carbonyl compounds, with the use of isolated enzymes or integral cells as catalysts $[4,5]$. Isolated enzymes are available commercially, and the equipment and procedures involved are generally simple, but the need for cofactors and the cost of these enzymes may be restrictive factors.

The use of intact cells presents some advantages since the enzymes are in their natural environment, thus avoiding the loss of activity by modifications in the protein structure, as well as allowing the regeneration of cofactors, when necessary [6]. On the other hand side reactions, caused by the presence of enzymatic complexes, may occur leading to mixtures of products, besides the low tolerance to organic solvents used to solubilize substrates with little solubility in water [7].

Although genetic engineering studies [1] have led to the discovery of new biocatalysts, one of the main sources is the existing biodiversity of animals, algae, plants and/or microorganisms that allows the search for new biocatalysts [8-10]. The microorganisms are distributed in all habitats, and reports of bacteria and fungi from terrestrial and marine biomass as catalysts in reactions of biocatalysis or biotransformation can be found [11-13]. In addition, of the hundreds of enzymes used in the industry, half are fungi, about a third of bacteria, the rest being from other sources, such as animals and plants, demonstrating the potential for application of microorganisms in this area [14].

Fungi are one of the most diverse groups and consequently one of the least known, it is estimated that there are about 1.5 million fungi in the world [15], of which only 5 to $7 \%$ of species have been described [16]. The semi-arid region, which occupies about $60 \%$ of the Brazilian northeast, has a diversity of fungi still unknown, both from a taxonomic and biotechnological point of view [17], among which are the fungi associated with the leaf, like the Periconia hispidula. This fungus was recently selected in our research group [11] as a producer of ketoredutases, through a screening involving 55 isolated conidial fungi in the semiarid and using acetophenone as a carbonyl substrate, thus justifying a more detailed investigation of their biocatalytic action.

\section{Materials and Methods}

\section{Microorganisms}

The conidial fungus Periconia hispidula (Pers.) EW Mason and MB Ellis [10], collected by Cruz, ACR in the Dunes of São Francisco, Bahia, belongs to the Collection of Culture of Microorganisms of the State of Bahia (CCMB) of Feira de Santana-BA. It presents a colony with a moderate growth, with brown coloration to dark chestnut in 
some points. The vegetative mycelium is superficial, with presence of hyaline hyphae, sporulating with approximately 7 days (Figure 1).
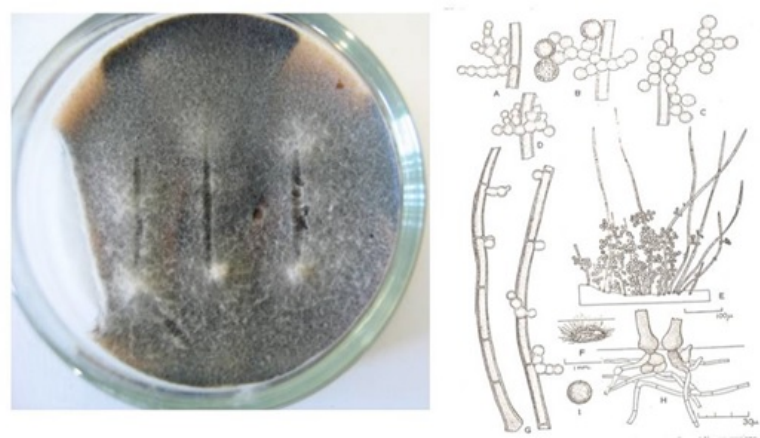

Figure 1: Culture of the fungus Periconia hispidula (on the right) and its structures (on the left) [12].

The experiments were carried out at the Laboratory of Chemistry of Natural and Bioactive Products of UEFS (Lapron). To maintain the viability of these microorganisms without morphological, physiological or genetic changes, the Castellani preservation method at room temperature was used.

To verify the purity and reactivation of the growth, the fungi were harvested in BDA (Both Dextrose Agar) agar medium, consisting of $39.0 \mathrm{~g}$ to $1 \mathrm{~L}$ of distilled water (HEMEDIA) and stored at $30^{\circ} \mathrm{C}$ in a Low Temperature Bio-Oxygen Demand Incubator (BOD) for 7 days.

\section{Standardization of biocatalyst}

In order to determine the stage of growth for substrate addition, 250 $\mathrm{mL}$ reagent flasks were used, containing $100 \mathrm{~mL}$ BD medium consisting of $24 \mathrm{~g}$ of dextrose potato and $1 \mathrm{~L}$ of previously sterilized distilled water. After cooling, 5 plugs ( $5 \mathrm{~mm}$ disc of mycelium) were added, which were stored on shaking in an orbital incubator (shaker) at $30^{\circ} \mathrm{C}$ and $150 \mathrm{rpm}$ for fungus growth. Upon completion of $96 \mathrm{~h}(\log$ phase) and $168 \mathrm{~h}$ (stationary phase) after inoculation $20 \mu \mathrm{l}$ of acetophenone was added to each treatment, they were kept under agitation during the reaction time.

The determination of the dry biomass ( $g$ ) was determined after separation of the mycelial mass by vacuum filtration followed by drying to constant weight in a drying oven at $60^{\circ} \mathrm{C}$ for $24 \mathrm{~h}$ of reaction.

Fermentation broths were collected with $2.0 \mathrm{~mL}$ of 24, 48, 72 and 96 hours of reaction, the product of which was extracted with $2.0 \mathrm{~mL}$ of ethyl acetate. All experiments were performed in triplicate.

\section{Optimization of the reaction medium}

Addition of substrate: In the assays for evaluation the substrate quantities, were performed in two ways: with intact cells, where the substrate was added during growth of the microorganisms and resuspended (resting cell). After $96 \mathrm{~h}$, where fungal mycelium growth in $\mathrm{BD}$ (log phase), medium was filtered to separate the mycelium and approximately $3 \mathrm{~g}$ of mycelium was suspended in reagent flasks containing $100 \mathrm{ml}$ of phosphate buffer, $\mathrm{pH}=5.9$, at $0.1 \mathrm{~mol} \mathrm{~L}^{-1}$ and $10 \%$ glucose. $20 \mu \mathrm{l}$ of acetophenone was added and the reaction occurred in the $30^{\circ} \mathrm{C}$ and $150 \mathrm{rpm}$ orbital incubator.
Influence of $\mathrm{Fe}^{2+}$ presence on the reaction medium: The evaluation occurred with $\mathrm{BD}$ medium with and without complementation to 0.02 $\mathrm{g} \mathrm{L}^{-1}$ of $\mathrm{Fe}_{2} \mathrm{SO}_{4}$ as cofactor.

Toxicity of acetophenone: The toxicity of acetophenone was evaluated by adding 5 different amounts of acetophenone $(20,50,100$, 150 and $200 \mathrm{mg}$ ) added in BD medium supplemented with $0.02 \mathrm{~g} \mathrm{~L}^{-1}$ of $\mathrm{Fe}_{2} \mathrm{SO}_{4} .2 .0 \mathrm{~mL}$ aliquots were collected at 24, 48, 72 and 96 hours.

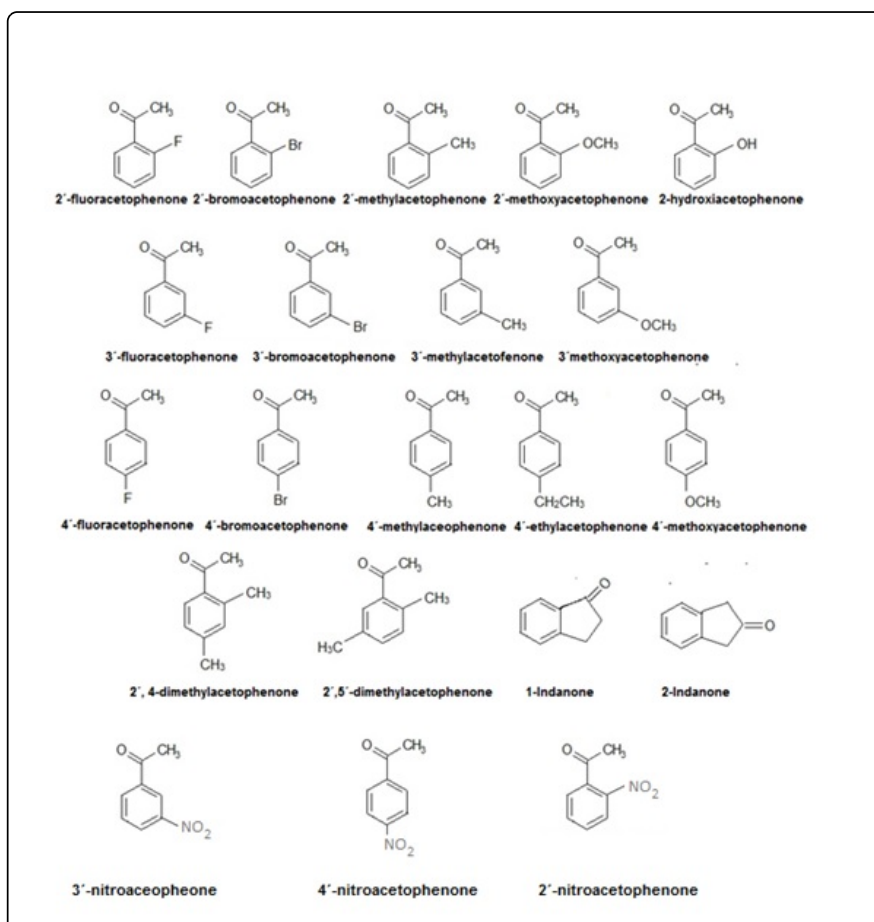

Figure 2: Structure of the substrates evaluated in the biorreduction by the fungus $P$. hispidula.

Reduction of acetophenone with sodium borohydride: To a $25 \mathrm{~mL}$ flask under stirring was added $5 \mathrm{~mL}$ of methanol, $1.25 \mathrm{~g}$ of sodium borohydride was dissolved and $50 \mathrm{~mol}$ of the ketone, dissolved in $5 \mathrm{~mL}$ of metanol, was added dropwise maintaining the temperature at $30^{\circ} \mathrm{C}$. After the addition, it remained under stirring for 30 minutes at room temperature.

The end of the reaction was determined by thin layer chromatography using hexane: ethyl acetate (8: 2). After the reaction was complete, $10 \mathrm{~mL}$ of a solution of $\mathrm{HCl}(10 \mathrm{M})$ was added. The methanol was evaporated under vacuum in the rotary evaporator and extracted with ethyl acetate $(3 \mathrm{x})$. The organic phase was dried with anhydrous $\mathrm{MgSO}_{4}$, filtered and concentrated under vacuum in the rotary evaporator.

The products were purified by column chromatography using Silica gel $60 \quad(0.040 \mathrm{~mm}-0.063 \mathrm{~mm}$ Merck $)$ with mixtures of the eluents:hexane:ethyl acetate. Yields were greater than $80 \%$.

Reactivity and selectivity of the biocatalyst against different aromatic ketones: The reactivity and selectivity of the biocatalyst against different aromatic ketones (Figure 2) were evaluated in assays with $\mathrm{BD}$ medium supplemented with $0.02 \mathrm{~g} \mathrm{~L}^{-1}$ of $\mathrm{FeSO}_{4} \cdot 7 \mathrm{H}_{2} \mathrm{O}$, after $96 \mathrm{~h}$ of growth $20 \mathrm{mg}$ of substrate was added, that reacted in $48 \mathrm{~h}$, and then total extraction of the reaction product was made. 
Citation: Serly S, Luis Fernando PG, Angelica L, Heiddy MA, Iván Sergio CG (2018) Periconia hispidula A New Semiarid Biocatalyst for the

Page 3 of 7

\section{Chromatographical analyzes}

Samples diluted in ethyl acetate were analyzed by gas chromatography (GC) on Varian CP-3380 brand equipment with DIC flame ionization detector, with chiral CYDEX-B column $(25 \mathrm{~m} \times 0.22$ $\mathrm{m} \times 0.22 \mu \mathrm{m}$ ) keeping a flow of $1 \mathrm{~mL} \mathrm{~min}^{-1}$ of He (helium) as entrainment gas. Using the analysis conditions of Table 1.

\begin{tabular}{|c|c|c|c|c|}
\hline $\begin{array}{l}\text { Substituents } \\
\left({ }^{*}\right)\end{array}$ & $\begin{array}{l}\text { Temp. } \\
\left({ }^{\circ} \mathrm{C}\right)\end{array}$ & $\begin{array}{l}\text { Rate } \\
\text { min. })\end{array} \quad\left({ }^{\circ} \mathrm{C} /\right.$ & $\begin{array}{l}\text { Residence time } \\
\text { (min.) }\end{array}$ & $\begin{array}{l}\text { Total } \\
\text { (min.) }\end{array}$ \\
\hline \multirow{2}{*}{--- } & 100 & --- & 0 & 0 \\
\hline & 150 & 5 & --- & 10 \\
\hline \multirow{2}{*}{$2^{\prime}-3^{\prime}-4^{\prime} \mathrm{Me}$} & 100 & --- & 10 & 10 \\
\hline & 200 & 10 & --- & 20 \\
\hline \multirow{2}{*}{ 2'- 3'- 4' MeO } & 140 & --- & 15 & 12 \\
\hline & 200 & 10 & --- & 21 \\
\hline \multirow{2}{*}{$2^{\prime}-3^{\prime}-4^{\prime} \mathrm{Br}$} & 140 & --- & 20 & 20 \\
\hline & 200 & 5 & --- & 31 \\
\hline \multirow{2}{*}{ 2'- 3'- 4' F } & 100 & --- & 10 & 10 \\
\hline & 200 & 10 & --- & 20 \\
\hline \multirow{2}{*}{ 2'- 4' NO2 } & 150 & --- & 12 & 12 \\
\hline & 200 & 15 & --- & 30 \\
\hline \multirow{2}{*}{ 3' NO2 } & 150 & --- & 30 & 30 \\
\hline & 200 & 5 & 2 & 42 \\
\hline \multirow{2}{*}{$2^{\prime}-4^{\prime} \mathrm{Me}$} & 100 & --- & 10 & 10 \\
\hline & 200 & 10 & 5 & 25 \\
\hline \multirow{2}{*}{ 2'- 5' Me } & 100 & --- & 10 & 10 \\
\hline & 200 & 10 & 5 & 25 \\
\hline \multirow{3}{*}{ 4' Et } & 70 & --- & --- & --- \\
\hline & 100 & 10 & 7 & 10 \\
\hline & 200 & 5 & 5 & 35 \\
\hline
\end{tabular}

$\left({ }^{\star}\right)$ Conditions: Chiral column Cydex B, column temperature $=200^{\circ} \mathrm{C}$ and injector temperature $=220^{\circ} \mathrm{C}$.

Table 1: Chromatographic conditions of gas chromatographic analyzes of acetophenone and its derivatives.

The products obtained with the biocatalysed reactions were analyzed and determined by GC-MS in SHIMADZU QP 2010 SE apparatus with RTX-MS dimethylpolysiloxane capillary column $(30 \mathrm{~m}$ $\times 0.25 \mathrm{~mm} \times 0.30 \mu \mathrm{m}$ ). In the analyzes, helium was used as drag gas in Split mode, operating with temperature gradients varying according to the sample. The heating programs were: $3^{\circ} \mathrm{C} / \mathrm{min}\left(60^{\circ}-80^{\circ} \mathrm{C}\right)$ and $50^{\circ} \mathrm{C} / \mathrm{min}\left(80^{\circ} \mathrm{C}-280^{\circ} \mathrm{C}\right)$ for 8 minutes with the injector temperature of $25^{\circ} \mathrm{C}$ and detector of $300^{\circ} \mathrm{C}$.
The quantitative analysis was obtained by integrating the Total Ion Chromatogram (TIC) and for the determination of conversion, the relationship between the acetophenone and 1-phenylethanol areas was used in the chromatograms, identified with authentic standards of acetophenone and 1-phenylethanol.

The enantiomeric purity was determined under the same conditions and calculation of the enantiomeric excess (ee) was defined as the ratio of $[(\mathrm{S})-(\mathrm{R}) /(\mathrm{S})+(\mathrm{R})] \times 100 \%$, wherein $(\mathrm{R})$ and $\mathrm{S})$ are the concentrations of the enantiomers, respectively.

The crude product was purified by silica column chromatography or preparative thin layer chromatography as eluents-hexane: ethyl acetate (9:1) to confirm structures by gas chromatography and mass spectrometry, in addition to determining the specific optical rotation.

\section{Results and Discussion}

\section{Standardization of the biocatalyst}

The growth curve of the fungus Periconia hispidula in the selected reaction medium was obtained by determining the dry biomass (DM) in grams for 12 days $(288 \mathrm{~h})$, in order to verify the growth profile of the isolate in its phases.

The results obtained are shown in Figure 3, where a subsequent exponential growth can be observed for 50 hours, thus maintaining up to about 150 hours. In this period of exponential growth, called the log phase, the enzymatic reactions have increasing velocity, reaching their maximum velocity at the beginning of the stationary phase [16].

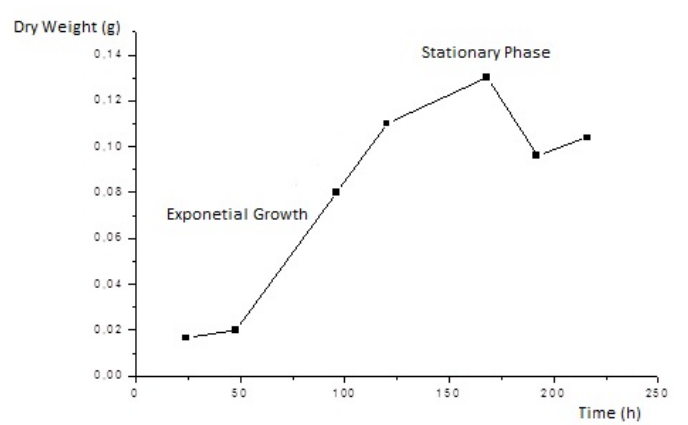

Figure 3: Growth curve of the fungus Periconia hispidula in BD medium.

Considering that in the stationary phase (at the maximum point of the exponential phase, $168 \mathrm{~h}$ ) the production of secondary metabolites is also increased, which may make it difficult to purify substances of interest in a biocatalysis reaction, it was decided to evaluate the biocatalytic action of the fungus after prior incubation for 96 hours (which corresponds to approximately half of the log phase). Table 2 shows the results obtained in the evaluation of different stages of growth, $\log$ and stationary, before addition of the substrate (Scheme 1). 
Citation: Serly S, Luis Fernando PG, Angelica L, Heiddy MA, Iván Sergio CG (2018) Periconia hispidula A New Semiarid Biocatalyst for the

Page 4 of 7

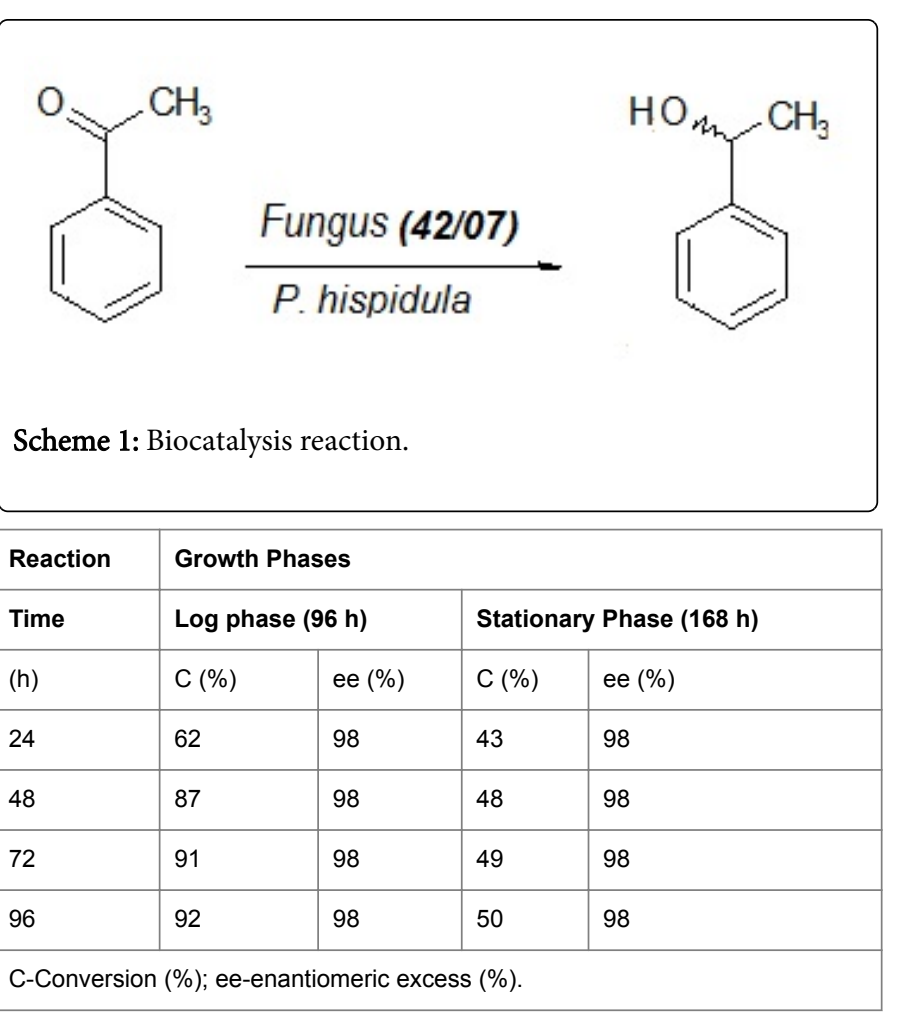

Table 2: Results obtained in the evaluation of different stages of growth, log and stationary, before addition of the substrate.

This decrease in conversion may have occurred due to the production of secondary metabolites by the fungus with inhibitory action on the enzymes present in the biocatalyst. As can be observed when the substrate was added in the stationary phase, the reaction occurs almost entirely (43\%) in the first 24 hours (Figure 4).

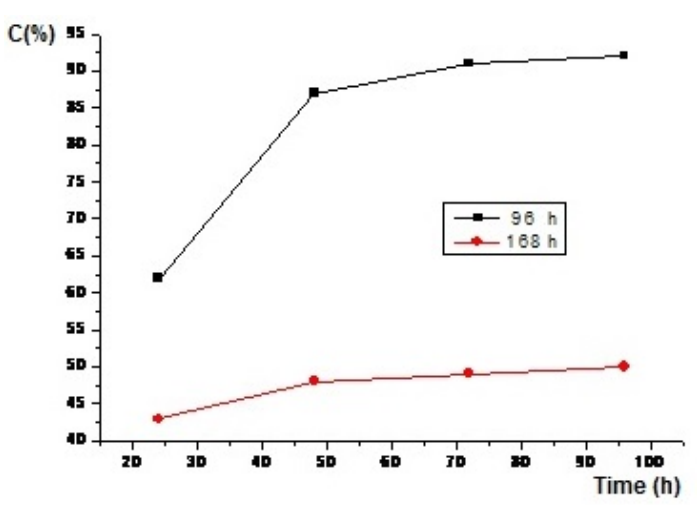

Figure 4: Conversion of the acetophenone biorreduction in S-1phenylethanol for 96 and $168 \mathrm{~h}$ of growth of the fungus Periconia hispidula in $\mathrm{BD}$ medium.

\section{Optimization of the reaction medium}

Substrate addition: Bioreduction reactions were performed in two ways: with whole cells of the growing and resuspending microorganism.
The results are shown in Table 3 demonstrating that the conversion is highest when the growing cell was used, reaching $92 \%$ conversion after 96 hours of reaction. However, the enantioselectivity had very small variations, remaining in the range of $95 \%$ to $98 \%$. Thus the catalyst in the form of growing cells was chosen for the subsequent experiments.

\begin{tabular}{|l|l|l|l|l|}
\hline \multirow{2}{*}{$\begin{array}{l}\text { Reaction Time } \\
\text { (h) }\end{array}$} & \multicolumn{2}{|l|}{ Growing Cells } & \multicolumn{2}{l|}{ Resting cells } \\
\cline { 2 - 5 } & C (\%) & ee (\%) & C (\%) & ee (\%) \\
\hline 24 & 50 & 97 & 15 & 95 \\
\hline 48 & 86 & 97 & 36 & 97 \\
\hline 72 & 90 & 98 & 47 & 97 \\
\hline 96 & 92 & 98 & 54 & 97 \\
\hline C-Conversion (\%); ee-enantiomeric excess (\%). \\
\hline
\end{tabular}

Table 3: Comparison of conversion and enantioselectivity for experiments with growing cells and resting cells.

Influence of the presence of $\mathrm{Fe}^{2+}$ in the reaction environment: Previous experiments performed by Machado [14] indicated that the presence of Iron Sulfate had a significant effect on the conversion and enantioselectivity of the acetophenone reduction reaction in 1-Sphenylethanol by the fungus Periconia hispidula, in YM medium. Considering this preliminary work the evaluation of the influence of the presence of iron sulphate in BD medium was also performed and the results are gathered in Table 4 .

\begin{tabular}{|c|c|c|c|c|}
\hline \multirow{3}{*}{$\begin{array}{l}\text { Time } \\
\text { Reaction } \\
\text { (h) }\end{array}$} & \multicolumn{4}{|c|}{ Influence of $\mathrm{Fe}^{2+}$} \\
\hline & \multicolumn{2}{|c|}{$0\left(g^{-1}\right)$} & \multicolumn{2}{|c|}{$0.02\left(\mathrm{~g} \mathrm{~L}^{-1}\right)$} \\
\hline & C (\%) & ee $(\%)$ & C (\%) & ee $(\%)$ \\
\hline 24 & 50 & 97 & 70 & 97 \\
\hline 48 & 86 & 97 & 90 & 98 \\
\hline 72 & 90 & 98 & 91 & 98 \\
\hline 96 & 92 & 98 & 92 & 98 \\
\hline
\end{tabular}

Table 4: Influence of the iron ion $\left(\mathrm{Fe}^{2+}\right)$ on the conversion (\%) of acetophenone to S-1-phenylethanol and enantioselectivity (\%) of the reaction catalyzed by the fungus Periconia hispidula.

The results noticed that there was no difference in the conversion values between the $\mathrm{BD}$ and $\mathrm{BD}$ medium with $\mathrm{Fe}^{2+}$. Although the $\mathrm{BD}$ medium with $\mathrm{Fe}^{2+}$ reaches higher conversion (70\%) after $24 \mathrm{~h}$ of reaction, in the other evaluated periods there is no difference in the conversion. That is, when iron was added $\left(\mathrm{Fe}^{2+}\right)$ in the $\mathrm{BD}$ medium the reaction occurred faster. The enantioselectivity is elevated for both experiments to about $98 \%$.

Acetophenone toxicity: The toxicity of the fungus Periconia hispidula to increase the amount of substrate above $20 \mu \mathrm{L}$ of acetophenone were tested in the following concentrations $50 \mu \mathrm{L}, 100$ $\mu \mathrm{L}, 150 \mu \mathrm{L}$ and $200 \mu \mathrm{L}$, as shown in Table 5 . 
Page 5 of 7

The effect of the toxicity of the substrate on the fungus Periconia hispidula was not observed until the addition of $50 \mu \mathrm{L}$ of the substrate, both for the conversion and for the enantiomeric excess, demonstrating that the enzymes produced by the fungus have a high selectivity, maintaining high conversion values and enantiomeric excess of the product (1-S-phenylethanol).

It was observed that when larger amounts of acetophenone 150 and $200 \mu \mathrm{L}$ were used as the substrate, the conversion was below $43 \%$ during the periods evaluated. The enantiomeric excess was drastically reduced from $83 \%$ to $40 \%$ with the addition of $200 \mu \mathrm{L}$ after $96 \mathrm{~h}$ of reaction. When the amount of the substrate was $150 \mu \mathrm{L}$ there was a $6 \%$ reduction of the enantiomeric excess. Adding $100 \mu \mathrm{L}$ yielded excellent results: conversion (96\%) and enantiomeric excess (98\%) after $96 \mathrm{~h}$ of reaction.

Concentrations below $100 \mu \mathrm{L}$ contribute to a faster reaction probably due to the decrease in the toxic effect of the substrate on the microorganisms since the experiments occurred with growing cells.

\begin{tabular}{|c|l|l|l|l|l|l|l|l|}
\hline $\begin{array}{l}\text { Concentration } \\
\text { of Substrate }(\boldsymbol{\mu L})\end{array}$ & \multicolumn{4}{|c|}{ Conversion (\%) } & \multicolumn{4}{|c|}{ Enantiomeric Excess (\%) } \\
\hline & $\mathbf{2 4} \mathbf{~ h}$ & $\mathbf{4 8 ~ h}$ & $\mathbf{7 2} \mathbf{~ h}$ & $\mathbf{9 6} \mathbf{~ h}$ & $\mathbf{2 4} \mathbf{~ h}$ & $\mathbf{4 8 ~ h}$ & $\mathbf{7 2 ~ h}$ & $\mathbf{9 6} \mathbf{~ h}$ \\
\hline 20 & 73 & 90 & 91 & 92 & 98 & 98 & 98 & 97 \\
\hline 50 & 70 & 91 & 96 & 96 & 98 & 98 & 98 & 98 \\
\hline 100 & 37 & 79 & 80 & 96 & 97 & 98 & 98 & 98 \\
\hline 150 & 20 & 30 & 36 & 43 & 89 & 89 & 84 & 83 \\
\hline 200 & 12 & 19 & 24 & 28 & 83 & 64 & 49 & 40 \\
\hline
\end{tabular}

C-Conversion (\%); ee-enantiomeric excess (\%).

Table 5: Conversion values (\%) and enantioselectivity (\%) of the bioreduction of acetophenone in 1-phenylethanol catalyzed by the fungus Periconia hispidula.

Reactivity and the selectivity of the biocatalyst against different aromatic ketones: The bioreduction of aromatic ketones was tested against the fungus Periconia hispidula for the production of alcohols in order to evaluate the influence of the aromatic ring substituents on the reactivity and enzymatic selectivity.

The reactivity and selectivity of the biocatalyst against different aromatic ketones were evaluated in assays with $\mathrm{BD}$ medium supplemented with iron, using growing cells and adding $20 \mathrm{mg}$ of substrate. The products formed were analyzed by gas chromatography.

Substituted acetophenones: The results for the bioremediation of mono and disubstituted acetophenone derivatives are listed in Table 6.

\begin{tabular}{|l|l|l|l|l|}
\hline Substituents & DB (g) & C (\%) & ee (\%) & Configuration \\
\hline $\mathrm{H}$ & 0.417 & 87 & 96 & $(\mathrm{~S})$ \\
\hline 2'-Me & 0.342 & $>99$ & $>99$ & $(\mathrm{~S})$ \\
\hline 3'-Me & 0.397 & 83 & 96 & $(\mathrm{~S})$ \\
\hline 4'-Me & 0.349 & 73 & 90 & $(\mathrm{~S})$ \\
\hline 2'-MeO & 0.360 & $>99$ & $>99$ & $(\mathrm{~S})$ \\
\hline 3'-MeO & 0.393 & 82 & $>99$ & $(\mathrm{~S})$ \\
\hline
\end{tabular}

\begin{tabular}{|c|c|c|c|c|}
\hline 4'-MeO & 0.335 & 56 & 79 & (S) \\
\hline $2^{\prime}-\mathrm{Br}$ & 0.217 & $>99$ & $>99$ & $(\mathrm{~S})$ \\
\hline 3'-Br & 0.352 & $>99$ & $>99$ & (S) \\
\hline $4^{\prime}-\mathrm{Br}$ & 0.280 & 97 & 54 & $(\mathrm{~S})$ \\
\hline 2'-F & 0.360 & $>99$ & $>99$ & $(\mathrm{~S})$ \\
\hline 3'-F & 0.255 & 98 & 96 & $(\mathrm{~S})$ \\
\hline $4^{\prime}-\mathrm{F}$ & 0.298 & 72 & $>99$ & (S) \\
\hline $2^{\prime}-\mathrm{NO}_{2}$ & 0.299 & $>99$ & $>99$ & (S) \\
\hline $3 '-\mathrm{NO}_{2}$ & 0.270 & $>99$ & $>99$ & (S) \\
\hline $4^{\prime}-\mathrm{NO}_{2}$ & 0.288 & 95 & 97 & $(\mathrm{~S})$ \\
\hline Substituents & DB (g) & C (\%) & ee $(\%)$ & Configuration \\
\hline 4'- Et & 0.325 & 56 & 54 & $(\mathrm{~S})$ \\
\hline 2',4'-Me & 0.384 & $>99$ & 96 & (S) \\
\hline 2',5'-Me & 0.370 & 94 & 99 & $(\mathrm{~S})$ \\
\hline
\end{tabular}

DB: Dry Biomass (g), conversion (\%) and enantioselectivity (\%). Reaction conditions: agitation- 150 r.p.m., temperature $30^{\circ} \mathrm{C}$, amount of substrate- $20 \mathrm{mg}$.

Table 6: Values of dry biomass (g), conversion (\%) and enantioselectivity (\%) of the bioreduction of the substituted acetophenones in chiral alcohols by the biocatalyst $P$. hispidula.
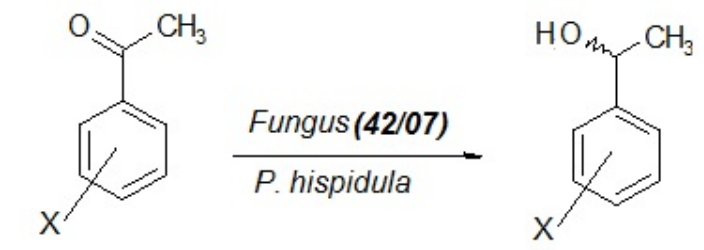

$$
\mathrm{X}=\mathrm{H}, \mathrm{OCH}_{3}, \mathrm{NO}_{2}, \mathrm{Br}, \mathrm{F}, \mathrm{CH}_{3}, \mathrm{OH}, \mathrm{Et}
$$

From the data obtained it can be observed that for the acetophenone derivatives where the substituent is in the ortho (2methylacetophenone, 2-methoxyacetophenone, 2-bromoacetophenone and 2-fluoracetophenone, 2-nitroacetophenone) derivatives to reduce the respective alcohols, $99 \%$ conversion and enantiomeric excess were obtained as the reaction time of $48 \mathrm{~h}$. In all cases, the absolute configuration of the alcohols was (S), following the Prelog rule.

Meta-substituted derivatives (3-bromoacetophenone, 3fluoracetophenone and 3-nitroacetophenone) have the best reduction results, with a conversion greater than $99 \%$ were obtained. However for the 3-methylacetophenone and the 3-methoxyacetophenone there was a decrease in conversion upto $80 \%$. However, the selectivities obtained remained high, higher than $96 \%$ and the configuration of the alcohols were Prelog (S) in all cases.

Although the electron-donor or electron-acceptor electron effect can also be noticed when the substituents are in positions 2 and 3, other types of effects may also act in these positions, such as the volume of the substituent group and the polar interactions with the active site of dehydrogenase, which may become predominant. This could justify the results for the derivatives in positions 2 and 3 , since in 
all cases; the respective chiral alcohols were obtained with high conversion values. For the derivatives with the substituent at 4 position (para), the results are interesting, as shown in Figure 5.

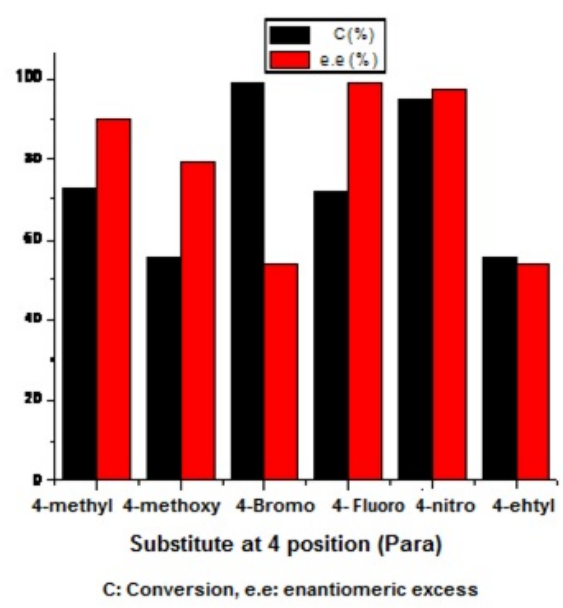

Figure 5: Comparison of the enantioselectivity and conversion of the monosubstituted acetophenone derivatives in the para position.

The reduction of the monosubstituted acetophenones with the 4fluoro and 4-nitro substituents obtained the best conversions of $72 \%$ and $95 \%$, respectively, and the enantiomeric excess of greater than $96 \%$.

4-bromoacetophenone despite of converted $97 \%$ of the substrate had $54 \%$ enantiomeric excess. This behavior may be associated with one of the disadvantages of the reduction of ketones involving whole cells is that the pro-S enzyme and pro- $\mathrm{R}$ dehydrogenase performance can compete for the substrate, which leads to the production of alcohol with low enantiomeric excess values [17].

The results obtained in the bioreduction of 4-fluoracetophenone may also be, because the volume of the atom has made it difficult to protect one of the faces of the carbonyl, since the bromine atom is larger than that of fluorine.

For the 4-methylacetophenone substituent, $73 \%$ conversion was achieved with 90\% enantiomeric excess and 4-methoxyacetophenone and 4-ethylacetophenone. Conversion (56\%) and enantiomeric excess values were as low as $79 \%$ and $54 \%$, respectively.

According to Rodrigues et al. the presence of electron withdrawing groups at position 4 provides a better transfer of hydride from NADH or NADPH to carbonyl carbon by the enzyme dehydrogenase present [17]. Thus, the best results of 4-nitroacetophenone in relation to 4methylacetophenone, 4-methoxyacetophenone and 4ethylacetophenone are explained. With the halogenated derivatives (4bromo and 4-fluoro) was not observed. Disubstituted acetophenones had high conversion and excellent enantiomeric excess higher than 94\%.

\section{Conclusion}

In this work, ketone reduction reactions were performed using the fungus Periconia hispidula, isolated from the Baiano semi-arid region, in the bioreduction of aromatic carbonyl compounds. Despite the biodiversity of microorganisms in this region, their biocatalytic potential is little explored.

Thus, the study carried out is important regrading to the use of the fungus Periconia hispidula as a biocatalyst.

- The stage to add the substrate was $96 \mathrm{~h}$.

- The optimized medium for the biocatalyst bio-reduction was the $\mathrm{BD}$ medium supplemented with $\mathrm{Fe}^{2+}$.

- The biocatalyst showed resistance to toxicity up to $100 \mathrm{mg}$ of acetophenone.

- The fungus Periconia hispidula biocatalyzed several aromatic carbonyl compounds with good conversion values and enantiomeric excess, in BD medium supplemented with $\mathrm{Fe}^{2+}$.

- The best results were for monosubstituted acetophenone derivatives in the ortho position. In the all cases studied, the conversion and the enantiomeric excess were greater than $99 \%$.

\section{References}

1. Bornscheuer UT, Huisman GW, Kazlauskas RJ, Lutz S, Moore JC, et al. (2012) Engineering the third wave of biocatalysis. Nature 485: 185-194.

2. Singh A, Goel Y, Rai AK, Banerjee UC (2013) Lipase catalyzed kinetic resolution for the production of (S)-3-[5-(4-fluoro-phenyl)-5-hydroxypentanoyl]-4-phenyl-oxazolidin-2-one: An intermediate for the synthesis of ezetimibe. J Molecu Catal B: Enzym 85: 99-104.

3. Gotor-Fernández V, Brieva R, Gotor V (2006) Lipases: Useful biocatalysts for the preparation of pharmaceuticals. J Molecu Catal B: Enzym 40: 111-120.

4. Solano DM, Hoyos P, Hernáiz MJ, Alcántara AR, Sánchez-Montero JM (2012) Industrial biotransformations in the synthesis of building blocks leading to enantiopure drugs. Biores Technol 115: 196-207.

5. De Carvalho CC (2011) Enzymatic and Whole Cell Catalysis: Finding New Strategies for Old Processes. Biotechnol Adv 29: 75-83.

6. Faber K (2011) Biotransformations in Organic Chemistry (6th Edn.,) Berlin: Editoral Springer-Verlag. p: 454.

7. Yang ZH, Luo L, Chang X, Zhou W, Chen GH, et al. (2012) Production of chiral alcohols from prochiral ketones by microalgal photo-biocatalytic asymmetric reduction reaction. J Indus Microbiol Biotechnol 39: 835-841.

8. Matsuda T, Yamanaka R, Nakamura K (2009) Recent progress in biocatalysis for asymmetric oxidation and reduction. Tetrah Asym 20: 513-557.

9. Borges KB, De Souza Borges W, Durán-Patrón R, Pupo MT, Bonato PS, et al. (2009) Stereoselective biotransformations using fungi as biocatalysts. Tetrah Asym 20: 385-397.

10. Sanchez S, Demain AL (2011) Enzymes and bioconversions of industrial, pharmaceutical and biotechnological significance. Org Proc Res Develop 15: 224-230.

11. Hawksworth DL (2001) The magnitude of fungal diversity: The 1.5 million species estimate revised. Mycolog Res 105: 1422-1432.

12. Gusmão LFP, Maia LC (2006) Diversity and characterization of the Brazilian semi-arid fungi. Recife:MCT/Associação Plantas do Nordeste, Brazil.

13. Gusmão LF, Marques MF (2006) Diversity of fungi in the Brazilian semiarid. Toward greater knowledge of the Brazilian semi-arid biodiversity. Brasilia, Brazil: Ministry of Sci Technol p: 83-86.

14. Machado SS (2012) Bioreduction of ketones by conidial fungi of Brazilian semiarid-147f. Thesis (PhD in Biotechnology)-Feira de Santana State University, Feira de Santana.

15. Mason EW, Ellis MB (1953) Periconia Curta. Mycolog Paper, pp: 56-72.

16. Black JG (2012) Microbiology: principles and explorations (8th Edn.,) John Wiley \& Sons: New Jersey, USA.

17. Rodrigues JAR, Morani PJS, Conceição GJA, et al. (2004) Recent Advances in the biocatalytic asymmetric reduction of acetophenones and 
Citation: Serly S, Luis Fernando PG, Angelica L, Heiddy MA, Iván Sergio CG (2018) Periconia hispidula A New Semiarid Biocatalyst for the Reduction of Prochiral Aromatic Ketone. Nat Prod Chem Res 6: 310. doi:10.4172/2329-6836.1000310

a, $\beta$-unsaturated carbonyl compounds. Food Technol Biotechnol 42: 295-303. 